\title{
Fundus Uteri
}

National Cancer Institute

\section{Source}

National Cancer Institute. Fundus Uteri. NCI Thesaurus. Code C12315.

The upper, rounded portion of the uterus which is opposite from the cervix. 